\title{
Erratum to: Builders and taphonomic processes of Bajocian coral patch reefs in the Moroccan Central High Atlas
}

\author{
Abdellah Ait Addi ${ }^{1}$ \\ Published online: 24 March 2016 \\ (C) Saudi Society for Geosciences 2016 \\ Erratum to: Arab J Geosci (2015) 8:8583-8600 \\ 10.1007/s12517-015-1796-5
}

The original version of this paper, unfortunately, contained errors.

The following are the necessary updates needed.

\section{In the abstract section}

The texts:

The coral assemblages are relatively diverse and represented by the genera Isastrea, Cosmophyllia, Edwardoseris, Kobymeandrea, Dimorpharaea, and Polystylidium, in addition to other branching forms.

Should be replaced by:

The coral assemblages are relatively diverse and are mainly represented by forms comparable with Isastrea, Microphyllia, Montlivaltia, Dendraraea, Cladophyllia and other branching forms.

\section{In corals part, p. 8593}

The text:

Corals are relatively diverse and are mainly represented by forms comparable with Isastrea, Comophyllia, Edwardoseris, Kobymeandra, Dimorpharaea, Polystylidium, Montlivaltia, Dendrarea, Cladophyllia, and other branched forms which

The online version of the original article can be found at http://dx.doi.org/ 10.1007/s12517-015-1796-5.

Abdellah Ait Addi

a.aitaddi@uca.ma

\footnotetext{
Geosciences \& Environmental Research Laboratory, Earth Sciences, Department, Faculty of Sciences and Techniques, Cadi Ayyad University, Abdelkarim EL Khattabi Street, P.O. Box 549-Guéliz, Marrakesh 40000, Morocco
}

can be compared to Acropora (according to B. Lathuilière, preliminary determination) and correspond to the typical composition of Lower Bajocian reef communities (Lathuilière 2000a, b)

Should be replaced by:

Corals are relatively diverse and are mainly represented by forms comparable with Isastrea, Microphyllia, Montlivaltia, Dendraraea, Cladophyllia and other branching forms. They seem to be close of the typical composition of Lower Bajocian reef communities (Lathuilière 2000a, b).

\section{In the conclusion, p. 8597}

The texts:

The most abundant genera are Isastrea, Comophyllia, Edwardoseris, Kobymeandra, Dimorpharaea, Polystylidium, and Montlivaltia.

Should be replaced by:

Genera comparable to Isastrea, Microphyllia, Montlivaltia, Dendraraea and Cladophyllia have been observed.

4. In the Acknowledgments, p. 8597

Because Prof. B. Lathuilière did not accept the acknowledgment, the following line should be removed:

Special thanks to Prof. B. Lathuilière (Nancy University, France) for preliminary determinations of some coral specimens.

5. In Fig 10 m caption, p. 8593: Chomatoseris should be replaced by Montlivaltia 